\title{
THERMAL AND OPTICAL PROPERTIES OF SILVER-POLYIMIDE NANOCOMPOSITE BASED ON DIPHENYL SULFONE MOIETIES IN THE MAIN CHAIN
}

\author{
KHALIL FAGHIHI ${ }^{1}$ AND MEISAM SHABANIAN²

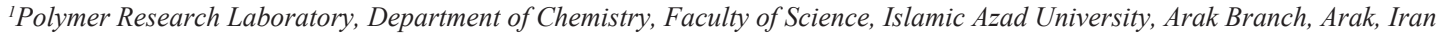 \\ ${ }^{2}$ Department of Chemistry, Farahan Branch, Islamic Azad University, Farahan, Iran
}

(Received: August 13, 2010 - Accepted: May 11, 2011)

\begin{abstract}
A new polyimide-silver nanocomposite containing diphenyl sulfone moiety in the main chain was synthesized using a convenient ultraviolet irradiation technique. $\mathrm{AgNO}_{3}$ was used as a source of the silver nanoparticles. Polyimide 3, as a polymer source , was synthesized by the polycondensation reaction of 4,4'-diamino diphenyl sulfone $\mathbf{1}$ with pyromellitic anhydride $\mathbf{2}$ in the presence of $i$ so-quinoline as base and $m$-cresol as solvent. The resulting composite film $\mathbf{3 a}$ was characterized by FTIR spectroscopy, Uv-vis analysis, X-ray diffraction (XRD), transmission electron microscopy (TEM), thermogravimetry analysis (TGA) and differential scanning calorimetry (DSC). The X-ray diffraction analysis reveals that silver nanoparticles are present in polyimide matrix. This data is in good agreement with the result obtained from TEM and shows the silver nanoparticles homogeneously dispersed in the polyimide matrix. The UV-vis spectrum shows a single peak at $425 \mathrm{~nm}$, arising from the surface plasmon absorption of the silver nanoparticles.
\end{abstract}

\section{INTRODUCTION}

Polyimides (PIs), especially aromatic polyimides, are the most famous high performance synthetic polymers with versatile properties, such as high transition temperatures, good chemical resistance, excellent mechanical properties, and outstanding thermal and thermo-oxidative stability. These properties have made polyimides the most widely used materials in many fields, including aerospace, electronics, and other modern industries. ${ }^{1-2}$ Metal-polymer hybrid nanocomposites have recently received much attention due to their potential to combine the features of polymeric materials with those of inorganic materials. Among the wide range of hybrid nanocomposite materials, metal-polymer nanocomposites and particularly silver-polymer nanocomposites are the subject of increased interest. Nanoscale metal particles such as silver represent promising functional fillers due to their specific electronic, optical, magnetic, catalytic, and antimicrobial properties..$^{3-4}$ Two major methods used to prepare the metal-polymer nanocomposite materials are dispersion of separately prepared colloidal metal nanoparticles in the polymer matrix ${ }^{5-6}$ and colloidal metal nanoparticles generated inside the polymer matrix from metal salts and complexes..$^{7-8}$ The later approach has been more frequently employed in recent years. A lot of reports are available on the synthesis of $\mathrm{Ag}$ nanoparticle using polyimide as matrix and silver nitrate as metal precursor in aqueous solution by different routes. ${ }^{9-11}$ In this article a new polyimide (PI)-silver nanocomposite containing diphenyl sulfone moiety in the main chain was prepared by using a facile ultraviolet irradiation technique at room temperature.

\section{EXPERIMENTAL}

\section{Materials}

4,4'-Diamino diphenyl sulfone, pyromellitic dinhydride, $m$-cresol, isoquinoline, $\mathrm{AgNO}_{3}$ and N-methyl-2-pyrrolidone (NMP) were purchased from Merck Chemical Company and used without previous purification.

\section{Techniques}

Fourier transform infrared (FTIR) spectra were recorded on a Galaxy Series FTIR 5000 spectrophotometer. UV-visible spectra were recorded at $25{ }^{\circ} \mathrm{C}$ in the $250-700 \mathrm{~nm}$ spectral regions with a Perkin Elmer Lambda 15 spectrophotometer in NMP solution using cell lengths of $1 \mathrm{~cm}$. Thermal Gravimetric Analysis (TGA and DTG) data were taken on a Mettler TA4000

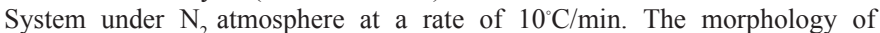
nanocomposite film was investigated on on a Hitachi H-800 transmission electron microscope with an accelerating voltage of $200 \mathrm{kV}$. Differential scanning calorimetric analysis were performed on differential scanning calorimeter (Du Pont 910 ) at a heating rate of $10^{\circ} \mathrm{C} / \mathrm{min}$.

Preparation of polyimide 3

A quantity of 5.0 mmole 4,4'-diamino diphenyl sulfone 1, 5.0 mmole pyromellitic anhydride 2 and two drops of iso-quinoline were dissolved in 25 $\mathrm{ml} m$-cresol, consecutively. The mixture was stirred at room temperature for 2 $\mathrm{h}$ and then at $180^{\circ} \mathrm{C}$ for $3 \mathrm{~h}$. The obtained PI solution was precipitated in 100 $\mathrm{ml}$ ethanol. The precipitate was immersed in distilled water and ethanol for 2 $\mathrm{h}$, and then washed with distilled water and ethanol several times to remove the residual $m$-cresol. The inherent viscosity of this soluble PI is $0.75 \mathrm{dL} / \mathrm{g}$.

\section{Preparation of polyimide-silver nanocomposite $3 a$}

A $250 \mathrm{~W}$ high-pressure mercury lamp was used as UV irradiation source. The $\mathrm{AgNO}_{3}$ was introduced as the source of $\mathrm{Ag}$ nanoparticles. First a solution of $1.0 \mathrm{~g}$ soluble PI in $8.0 \mathrm{ml} \mathrm{NMP}$ and also a solution of $1.0 \mathrm{mmole} \mathrm{AgNO}_{3}$ and 1.2 mmole TFA in $5.0 \mathrm{ml}$ NMP were prepared. Then the two solutions were mixed and irradiated for $12 \mathrm{~h}$ to ensure the complete reduction of $\mathrm{AgNO}$ under ultraviolet irradiation at room temperature. The product was precipitated quickly to distilled water and washed with distilled water several times. Then the sample was dried in vacuum, redissolved in chloroform by sonication, cast on a glass substrate, and vacuum dried at $50{ }^{\circ} \mathrm{C}$ for two days.

\section{RESULTS AND DISCUSSION}

Polyimide 3 was synthesized by reaction of an equimolar mixture of 4,4-diamino diphenyl sulfone sulfone $\mathbf{1}$ with pyromellitic dinhydride $\mathbf{2}$ in $m$-cresol and in the presence of iso-quinoline as a base (Scheme 1).

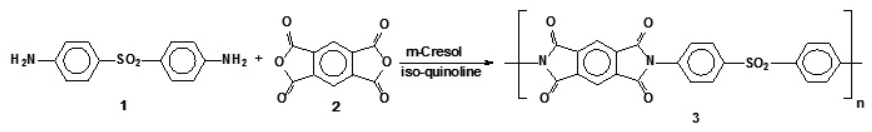

Scheme 1: Synthetic route of PI 3

The FT-IR spectrum of PI 3 exhibits characteristic absorption peaks for $\mathrm{C}=\mathrm{O}$ unsymmetrical stretching of imide groups (at $1783 \mathrm{~cm}^{-1}$ ), $\mathrm{C}=\mathrm{O}$ symmetrical stretching of imide groups (at $1722 \mathrm{~cm}^{-1}$ ) and $\mathrm{C}-\mathrm{N}$ stretching of imide groups (at $1383 \mathrm{~cm}^{-1}$ ). These bands show that PI $\mathbf{3}$ has been successfully synthesized. In addition, no obvious difference between the infrared spectra of the pure PI 3 and the PI-silver nanocomposite 3a was observed (Fig. 1). 


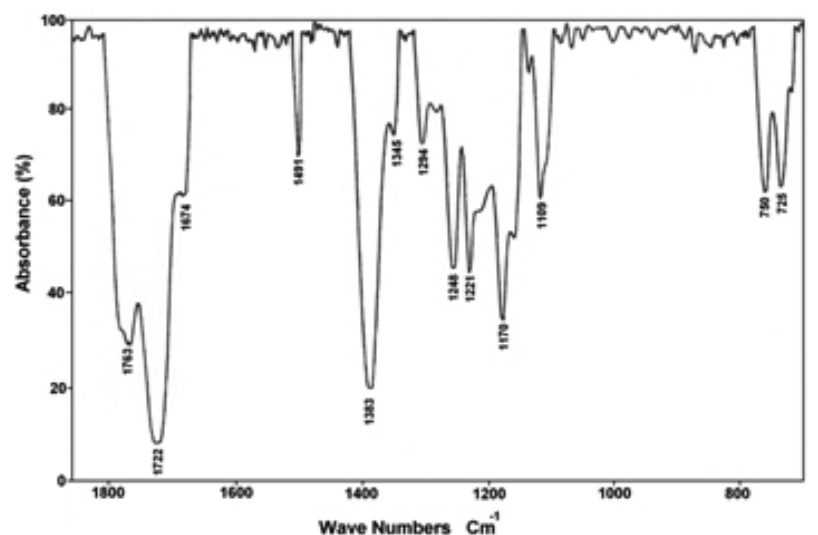

Fig. 1: FTIR spectrum of polyimide 3.

The XRD patterns of polyimide-Ag nanocomposite further confirmed the incorporation of silver nanoparticles in the composites as shown in Fig. 2. The weak reflection centered at a $2 \theta$ value around $20^{\circ}$ was characteristic of the amorphous polyimide..$^{12}$ Another five sharp diffraction peaks at $2 \theta$ values of $38.2,44.4,64.5,77.3$ and $81.5^{\circ}$ corresponded to Bragg's reflections from the (111), (200) (220), (311) and (222) planes of Ag and were in good agreement with the reported data. ${ }^{13}$

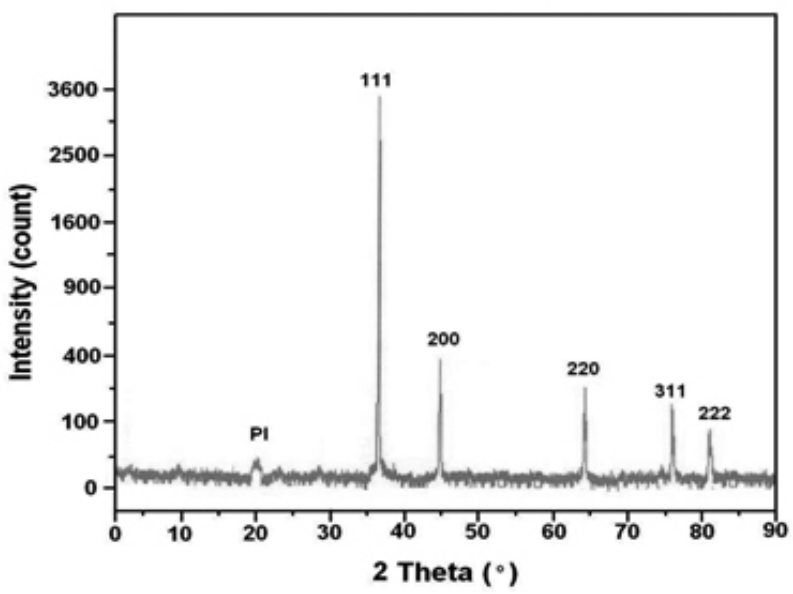

Fig. 2: XRD of polyimide-silver nanocomposite 3a

The TEM micrograph of the PI-silver nanocomposite 3a in figure 3 shows that the silver nanoparticles were close to homogeneously dispersed in the polyimide matrix.

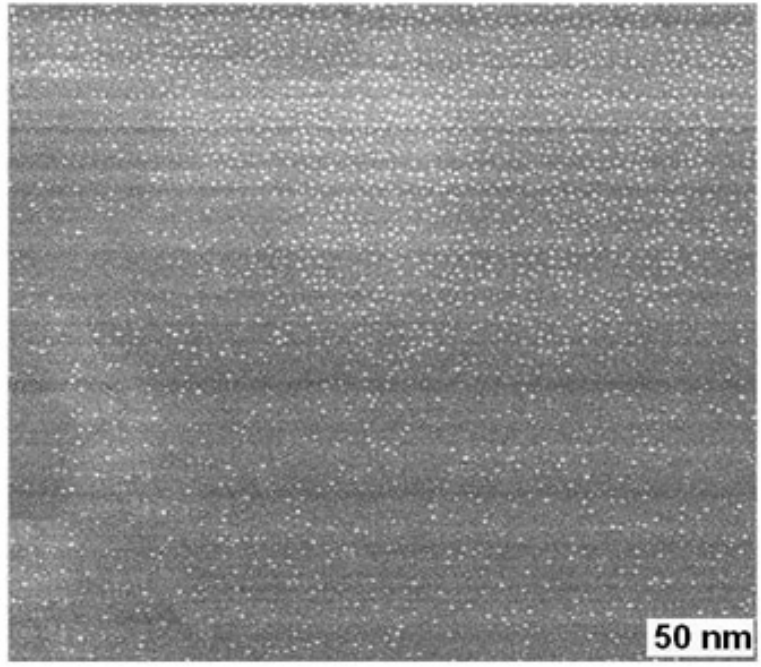

Fig. 3: TEM of polyimide-silver nanocomposite film 3a

Figure 4 represents the UV-Visible absorption of PI film $\mathbf{3}$ and prepared polyimide- $\mathrm{Ag}$ nanocomposite 3a. This figure shows a broad absorption characteristic band at $\lambda_{\mathrm{Max}}=425 \mathrm{~nm}$ due to the oscillation of conduction band electrons of Ag, known as the surface plasmon resonance. ${ }^{9}$ The position of the plasmon absorption bands depends on particle size, aspect ratio and diameter of embedded nanoparticles. ${ }^{14}$

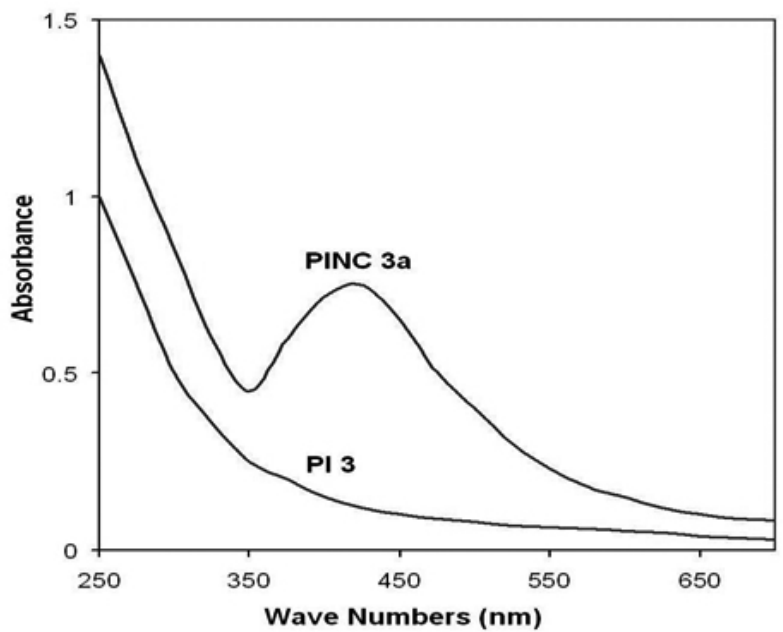

Fig. 4: Uv-Vis spectra of polyimide 3 and polyimide-silver nanocomposite film $3 \mathrm{a}$

Thermal Properties: The thermal properties of pure polyimide 3 and polyimide-silver nanocomposite $\mathbf{3 a}$ were investigated by TGA (in a nitrogen atmosphere at a heating rate of $10^{\circ} \mathrm{C} / \mathrm{min}$ ) and DSC experiments and the results are summarized in Table 1. The initial decomposition temperatures of 5 and $10 \%$ weight losses $\left(\mathrm{T}_{5}\right.$ and $\mathrm{T}_{5}$ ) and the char yield at $600^{\circ} \mathrm{C}$ for these samples are summarized in Table 1. The temperature of 5 and $10 \%$ weight loss and also the char yield at $600^{\circ} \mathrm{C}$ of polyimide-silver nanocomposite $3 \mathrm{a}$ were higher than the pure PI 3. The higher thermal stability of nanocomposite 3a can be attributed to the presence of inorganic silver nanoparticles into the polyimide matrix. 


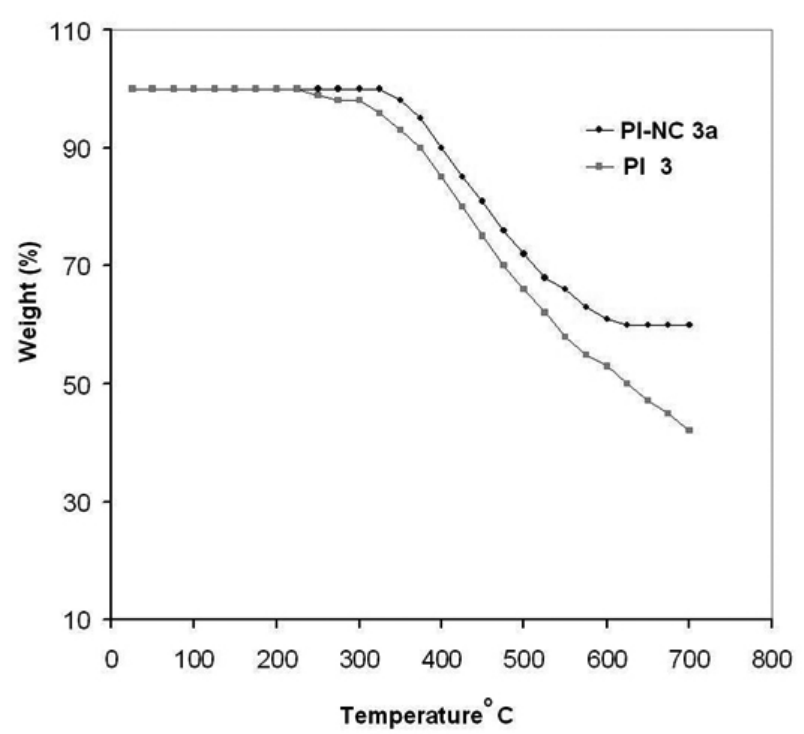

Fig. 5: TGA thermograms of PI 3 and polyimide-silver nanocomposite film 3a

Table 1: Thermal behaviors of polyimide 3 and polyimide-silver nanocomposite $3 \mathrm{a}$.

\begin{tabular}{|c|c|c|c|c|}
\hline Polyimide & $\mathrm{Tg}^{\mathrm{a}}$ & $\mathrm{T}_{5}\left({ }^{(} \mathrm{C}\right)^{\mathrm{b}}$ & $\mathrm{T}_{10}\left({ }^{\circ} \mathrm{C}\right)^{\mathrm{c}}$ & $\begin{array}{c}\text { Char } \\
\text { Yield }\end{array}$ \\
\hline $\mathbf{3}$ & 180 & 330 & 375 & $53 \%$ \\
\hline $\mathbf{3 a}$ & 185 & 375 & 400 & $61 \%$ \\
\hline
\end{tabular}

${ }^{a}$ The glass-transition temperatures (Tg) were measured by DSC. b,c Temperature at which $5 \%$ and $10 \%$ weight loss was recorded by TGA at heating rate of $10^{\circ} \mathrm{C} / \mathrm{min}$ in $\mathrm{N}_{2}$ respectively ${ }^{d}$ Percentage weight of material left undecomposed after TGA analysis $600^{\circ} \mathrm{C}$.

Also the Tg of nanocomposite 3a was higher than pure polyimide $\mathbf{3}$ (Table 1). Silver nanoparticles reduced the segmental motion of the polyimide chains and with increasing proportion of the inorganic phase shifted the baseline of DSC curve towards higher temperature.

\section{CONCLUSION}

In this work, a polyimide-silver nanocomposite film was successfully prepared by a convenient reduction of silver by ultraviolet irradiation technique. Ag-PI nanocomposite film has been synthesized at room temperature by the dispersion of aqueous $\mathrm{AgNO}_{3}$ to a solution of polyimide in NMP. The silver nanoparticles were homogeneously dispersed in the polyimide matrix. This result was confirmed by XRD measurement and using UV-vis and SEM analyses. The UV-vis spectrum confirmed the formation of silver nanoparticle with a surface plasmon band at $425 \mathrm{~nm}$. The high char yield of this nanocomposite film can be related the presence of inorganic silver nanoparticles in the polyimide matrix. These properties can make this nanocomposite attractive for practical applications such as processable highperformance engineering plastics.

\section{REFERENCES}

1. Ghosh, M. K.; Mittal, K. L. Polyimides: Fundamentals and Applications. Marcel Dekker, New York (1996).

2. Mittal, K. L. Polyimides: Synthesis, Characterization, and Applications. Plenum Press, New York (1984).

3. Clemenson, S.; Leonard, D.; Sage, D.; David, L.; Espuche, E. J. Polym. Sci. A, 46, 2062 (2008)

4. Temgire, M. K.; Joshi, S. S. Radiat. Phys. Chem. 71, 1039 (2003).

5. Radheshkumar, C.; Munstedt, H. Mater. Lett. 59, 1949 (2005).

6. Zhang, Z.; Han, M. J. Mater. Chem. 13, 641(2003).

7. Compton, J. M.; Thompson, D. W.; Kranbuehl, D. E.; Ohl, S.; Gain, O.; David, L.; Espuche, E. Polymer 47, 5303 (2006).

8. Espuche, E.; David, L.; Rochas, C.; Afeld, J. L.; Compton, J. M.; Thompson, D. W.; Kranbuehl, D. E. Polymer 46, 6657 (2005).

9. Huang, J. C.; Qian, X. F.; Yin, J.; Zhu, Z. K.; Xu, H. J. Mater. Chem. Phys. 69, 172 (2001).

10. Southward, R. E.; Thompson, D. W. Chem. Mater. 16, 1277 (2004).

11. Li, Y.; Lu, Q.; Qian, X.; Zhu, Z.; Yin, J. Appl. Surf. Sci. 233, 299 (2004).

12. Yang, Y.; Liu, S.; Kimura, K. Angew. Chem., Int. Ed. 45, 5662 (2006).

13. Sadjadi, M. A. S.; Sadeghi, B.; Meskinfam, M.; Zare, K.; Azizian, J. Physica E. 40, 3183 (2008).

14. Khanna, P.K.; Singh, N.; Charan, S.; Subbarao, V. V. S.; Gokhale, R.; Mulik, U. P. Mater. Chem. Phys. 93, 117 (2005). 